\title{
Treatment of Forefoot Problems in Older People: A Randomized Clinical Trial Comparing Podiatric Treatment With Standardized Shoe Advice
}

Babette C. van der Zwaard, $P b D^{1,2}$

Henriëtte E. van der Horst, MD, $\mathrm{PbD}$, Professor ${ }^{1}$

Dirk L. Knol, $P b D^{3}$

Benedicte Vanwanseele, $\mathrm{PbD}^{2,4}$

Petra J. M. Elders, MD, $P b D^{1}$

'EMGO+ Institute, Department of General Practice and Elderly Care Medicine, VU University Medical Centre, Amsterdam, The Netherlands

${ }^{2}$ Lectoraat, Fontys University for Applied Sciences, Eindhoven, The Netherlands

${ }^{3} \mathrm{EMGO}+$ Institute, Department of Epidemiology and Biostatistics VU University Medical Centre, Amsterdam, The Netherlands

${ }^{4}$ Department of Kinesiology, KU Leuven, Leuven, Belgium

sin

MORE ONLINE

www.annfammed.or
Conflicts of interest: authors report none.

\section{CORRESPONDING AUTHOR}

Babette van der Zwaard EMGO+ Institute for Health and

Care Research

VU University Medical Centre

BS7 Room 5.36

Postbus 7057

1007 MB Amsterdam

The Netherlands

b.vanderzwaard@vumc.nl

\begin{abstract}
PURPOSE Consultations for forefoot pain are frequent in primary care, but scientific support of treatment options is scarce. The purpose of this study is to investigate the effect of podiatric treatment vs standardized advice on proper shoe characteristics and fit of shoes by means of an information leaflet for people aged 50 years and older with forefoot pain in primary care.
\end{abstract}

METHODS In this randomized controlled trial, 205 participants aged 50 years and older with hindering nontraumatic forefoot pain have been recruited at their general practitioner's office. Exclusion criteria were treatment of forefoot problem of less than 6 months' duration before inclusion, rheumatoid arthritis, and diabetic neuropathy or having pain considered not to be musculoskeletal (eg, warts). Participants received shoe advice by means of an information leaflet or podiatric care. Foot pain, foot-related dysfunction, general health, and social participation were assessed by means of questionnaires every 3 months for 1 year. Using multilevel analysis, we analyzed results at the level of (1) outcome measures, (2) the individual, and (3) the general practitioner.

RESULTS No differences were found between the 2 treatment groups. Both intervention groups showed an improvement over time in foot pain and footrelated dysfunction.

CONCLUSION This study found that shoe advice provided to patients consulting their general practitioner for forefoot pain and symptom relief resulted in outcomes similar to treatment outcomes in patients consulting a podiatrist. Based on these results, primary care physicians should be cautious when referring a patient to a podiatrist; instead, they should start by providing advice on proper characteristics and fit of shoes.

Ann Fam Med 2014;12:432-440. doi: 10.1370/afm.1684.

\section{INTRODUCTION}

$\mathrm{F}$ oot pain is common and increases with age. Epidemiologic research found a prevalence of $22 \%$ to $25 \%$ in the adult general population. ${ }^{1,2}$ For every 10,000 registered patients in the Netherlands and the United Kingdom, a general practitioner will be consulted for foot and ankle pain 249 to 290 times a year, mostly for nontraumatic conditions. ${ }^{1,3}$ Complaints of foot pain make up $8 \%$ of all musculoskeletal ${ }^{1}$ and $17.6 \%$ of all lower extremity consultations. ${ }^{3}$

Women have foot pain more often than men ${ }^{2}$ and consult their general practitioner for it more often. ${ }^{1}$ The location where most foot pain occurs is the forefoot. ${ }^{4,5}$ More specifically, $53.7 \%$ of foot pain is located in the toes (including ingrown toenails) ${ }_{1}^{6} 32.5 \%$ to $37.2 \%$ is located on the dorsal side of the forefoot, ${ }^{6,7}$ and $24.3 \%$ to $37.2 \%$ is located on the plantar side or the ball of foot. ${ }^{7}$ Metatarsalgia, hallux valgus, hallux limitus, and lesser toe deformities are some diagnoses related to forefoot pain. ${ }^{4,8,9}$ Foot pain in general has been associated with an increased risk of falling and therefore an increased risk of fractures ${ }_{1}^{10,11}$ decreased mobility, ${ }_{1}^{4,12}$ and a decreased sense of well-being., ${ }^{5,73-15}$ 
In the Netherlands the general practitioner will most often prescribe anti-inflammatory medications for foot pain. ${ }^{16}$ Other possibilities are referring the patient to a specialist (eg, podiatrist, chiropodist, orthopedic surgeon) or providing lifestyle advice (eg, wear better shoes, lose weight). Currently, only the reduction of pain intensity after surgical treatment of painful hallux valgus has been scientifically established. ${ }^{17} \mathrm{We}$ were unable to locate any studies comparing other alternatives of managing forefoot pain. The most common choice for the general physician is referral to a podiatrist $t_{i}$ however, providing shoe advice (eg, advice on appropriate fit and general shoe characteristics) is a simple and low-cost form of treatment. Dutch podiatrists treat foot problems mainly by manufacturing insoles or using other noninvasive methods; they do not perform any invasive treatment. ${ }^{18}$ Wearing improper shoes is assumed to affect foot problems negatively even though a causal relationship has not been studied. ${ }^{19-22}$ The purpose of this study was to investigate the effect of podiatric treatment compared with that of standardized shoe advice on foot pain, foot disability, quality of life, and social participation in people aged 50 years and older with hindering forefoot pain.

\section{METHODS}

\section{Trial Design}

The design of this study was published in detail elsewhere. ${ }^{23}$ In short, we performed a pragmatic randomized controlled trial in the setting of general practices in which referral of patients with forefoot problems to a podiatrist was compared with standardized advice to wear shoes of good quality and fit by means of a shoe advice leaflet (Supplemental Appendix 1), with a follow-up period of 1 year. The medical ethical committee of the VU medical center has approved the study (2009/267).

\section{Participants}

Twenty-four general practices, distributed over 15 locations, comprising approximately 79,000 patients, participated in the study (Supplemental Appendix 2). Prospective participants were invited to participate by their physician during a consultation, by a letter if a search in the electronic medical information system had indicated that the patient had consulted the physician for forefoot pain in a 12-month period before March 2010 , or by posters in the waiting area in the physicians' offices. The inclusion lasted from March 2010 until April 2012. Inclusion criteria were age 50 years or older, having nontraumatic forefoot pain of more than 3 months' duration causing a functional impediment, and willingness to be randomized. Exclusion criteria were treatment for the forefoot pain less than 6 months before study inclusion, rheumatoid arthritis, diabetic neuropathy, or having foot pain that was not considered to be musculoskeletal (eg, warts, evaluated during a physical examination). People who were interested in the study received a screening form (exclusion criterion questions, pain location on a foot manikin, and the Manchester Foot Pain and Disability Index, MFPDI). Patients who met the inclusion criteria according to the screening form were invited for an examination to test for possible exclusion criteria before final inclusion in the study. Senior podiatric students performed the examination and were supervised by a human movement scientist who was also a lecturer in podiatry. The physical examination consisted of neuropathy screening (10-g monofilament, $128-\mathrm{Hz}$ tuning fork), photographs of feet and shoes, assessing foot posture, barefoot and in-shoe pressure assessment, and footwear assessment.

\section{Interventions}

Participants were randomly allocated either to receive shoe advice or to be referred to a podiatrist. The participants referred to a podiatrist received the address and telephone number of a podiatrist located near their home. By allocating participants to a specific podiatrist, we were able to refer participants as evenly as possible among the 17 participating podiatrists. Except for one instance, all podiatrists located near the participating general practitioners consented to treat patients in our trial.

Those provided with shoe advice acquired a leaflet containing advice on shoe characteristics and proper fit. ${ }^{24}$ The content of the leaflet was explained to participants by the first author, who used their current footwear to illustrate the content.

\section{Outcomes}

Participants received a questionnaire at baseline and every 3 months after inclusion until 12 months. Primary outcome measures were foot pain and foot function. Both constructs have been measured with several questionnaires. The measurement properties of these instruments had not been completely established, so using multiple outcome measures increases the reliability of the findings provided that the different instruments agree on the changes in outcome. Foot pain was measured using an 11-point pain intensity numerical rating scale (PI-NRS), ${ }^{25}$ the pain subscale of the 5-point Foot Function Index (FFI-5pt), ${ }^{26}$ and the pain subscale of the MFPDI. ${ }^{27}$ Foot dysfunction was measured using the foot dysfunction subscale of the FFI-5pt and the function subscale of the MFPDI. ${ }^{27}$ The 7-item FFI-5pt pain scale ranges from "no pain" to "intense pain" and the 8-item dysfunction scale from 
"no difficulty" to "impossible," both in 5-level increments. The MFPDI is scored as "none of the time," "on some days," and "on most/every day(s)." Secondary outcomes were general health, measured with the 12-Item Short Form Health Survey (SF-12), ${ }^{28}$ and social participation, measured with the Keel Assessment of Participation. ${ }^{29}$ Adherence was also assessed in every questionnaire. If the podiatric treatment (orthotics or other) were worn more than 3 days a week at 2 or more time points, participants were considered to be adherent. Participants in the shoe advice group were considered to be adherent if they indicated that they had bought new shoes using the folder or had chosen to wear shoes that were-in the opinion of the partici- pant-(more) consistent with the leaflet during the first 6 months after inclusion.

\section{Sample Size}

We needed complete data from 75 participants in each study group to detect a 1-point difference in improvement between the groups after 12 months, with a 1 -sided significance of .05 , assuming a power of 0.8 , an interclass correlation coefficient between podiatrists and general practitioners of 0.05 , a correlation of 0.50 between repeated measurements, and a minimum of 5 patients per physician. We wanted to enroll 100 patients in each of the 2 groups to allow for a dropout rate of $25 \%$ during follow-up.

\section{Figure 1. Participation flowchart.}

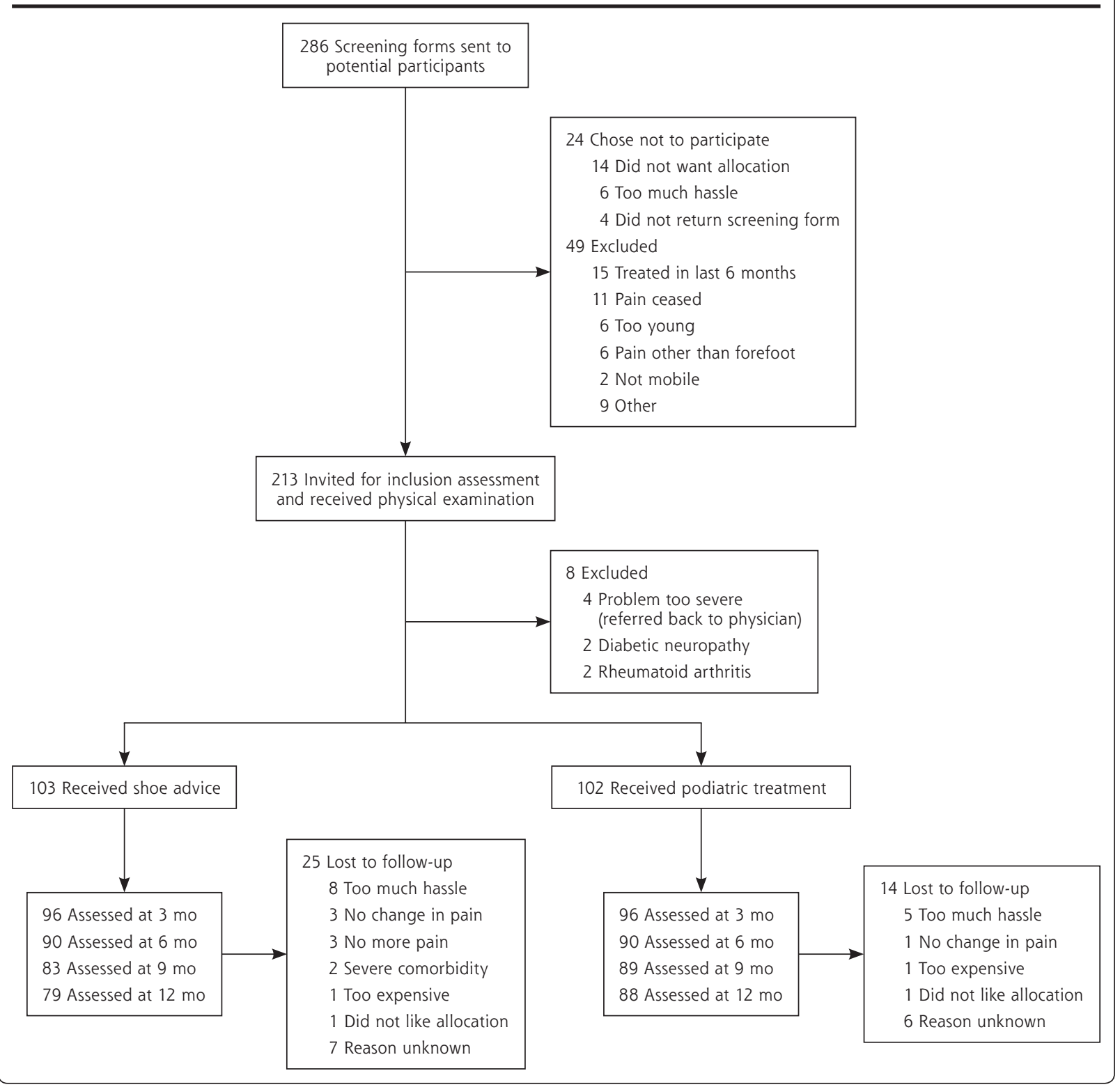




\section{Randomization}

Sex and age were prestratified during randomization: younger than 75 years, 8 per stratum, 75 years and older, 4 per stratum. Participant assignment to the study group was generated with random allocation software. Participants received an assignment envelope after the physical examination.

\section{Statistical Methods}

Data analysis was performed blinded. First, all participants were analyzed in the original group regardless of whether they received the allocated treatment (intention-to-treat principle). Data were tested for normality using visual evaluation Q-Q plots, and skewness of less than 1.0 is considered a normal distribution. Baseline values for both study groups were compared using a $\chi^{2}$ test $(P$ $<.05)$. Data were analyzed with multilevel analyses using MLwiN. ${ }^{30}$ Fixed effects were time (baseline, 3, 6, 9, and 12 months) and the group- (shoe advice, podiatrist) by-time interaction. The group-by-time interaction was the effect of interest. ${ }^{31}$ Level $1 \mathrm{com}$ prised the different outcome measures, level 2 comprised the individuals, and level 3 , the general physicians, was the highest level in the model. A random intercept was assumed for the level 3 (between physician) variances, and an unstructured covariance matrix was assumed for the repeated measurements of patients at the different time points. Both stratification variables (eg, sex and age) and an interaction term age* sex were added to the model to correct for the influence of these variables on the error variance of the model. Subsequently, the same analysis was repeated after exclusion of all nonadherent participants using the definitions as previously described (according to protocol analysis). The sample size of the study was calculated for the intention to treat analysis. $P$ values were adjusted using the Šidák approach for multiple comparisons.

\section{RESULTS}

\section{Participants}

Of the 286 individuals who were interested in participating in the study, 213 were invited for the screening examination (Figure 1). A total of 205 participants were included in the trial: 103 in the shoe advice group, and 102 in the podiatry group. Recruitment ceased when the desired sample size of 100 participants per group was attained. The participants' characteristics
Table 1. Baseline Characteristics of Study Participants

\begin{tabular}{|c|c|c|c|}
\hline Variable & $\begin{array}{c}\text { Total } \\
\text { Population } \\
\mathrm{N}=205\end{array}$ & $\begin{array}{c}\text { Shoe } \\
\text { Group } \\
n=103\end{array}$ & $\begin{array}{c}\text { Podiatry } \\
\text { Group } \\
n=102\end{array}$ \\
\hline \multicolumn{4}{|l|}{ Demographic characteristics } \\
\hline Age (SD), y & $64(9.3)$ & $64(9.8)$ & $64(8.9)$ \\
\hline Sex, female, No. (\%) & $159(77.9)$ & $81(79.4)$ & $78(76.5)$ \\
\hline \multicolumn{4}{|c|}{ First attention to research project, No, (\%) } \\
\hline Letter from general practitioner & $52(25.4)$ & $25(24.5)$ & $27(26.5)$ \\
\hline During visit to general practitioner & $76(37.1)$ & $39(38.6)$ & $37(36.3)$ \\
\hline Poster in waiting area & $44(21.5)$ & $25(24.8)$ & $19(18.6)$ \\
\hline Other & $30(14.7)$ & $12(11.8)$ & $18(17.6)$ \\
\hline Missing & $2(1.0)$ & $1(1.0)$ & $1(1.0)$ \\
\hline \multicolumn{4}{|l|}{ Education, No. (\%) } \\
\hline Primary school & $17(8.3)$ & $12(11.8)$ & $5(4.9)$ \\
\hline High school & $45(22.0)$ & $23(22.5)$ & $22(21.6)$ \\
\hline Vocational training & $77(37.7)$ & $39(38.2)$ & $38(37.2)$ \\
\hline Bachelor degree & $41(20.0)$ & $15(14.7)$ & $26(25.5)$ \\
\hline Master degree or higher & $20(9.8)$ & $12(11.8)$ & $8(7.8)$ \\
\hline Missing & $4(2.0)$ & $1(1.0)$ & $3(2.9)$ \\
\hline \multicolumn{4}{|l|}{ Pain history } \\
\hline \multicolumn{4}{|c|}{ Duration of pain before inclusion, No. (\%) } \\
\hline $3-6 \mathrm{mo}$ & $49(23.9)$ & $18(17.5)$ & $31(30.4)$ \\
\hline $6-12 \mathrm{mo}$ & $23(11.2)$ & $13(12.6)$ & $10(9.8)$ \\
\hline $12-24 \mathrm{mo}$ & $33(16.1)$ & $17(16.5)$ & $16(15.7)$ \\
\hline$>24 \mathrm{mo}$ & $92(44.9)$ & $51(49.5)$ & $41(40.2)$ \\
\hline Missing & $8(3.9)$ & $4(3.9)$ & $4(3.9)$ \\
\hline $\begin{array}{l}\text { Missed work because of foot prob- } \\
\text { lems in last } 3 \mathrm{mo}, \mathrm{No}(\%)^{\mathrm{a}}\end{array}$ & $8(11.9)$ & $5(14.7)$ & $3(9.0)$ \\
\hline \multicolumn{4}{|c|}{ Pain in other lower extremity joints in last month, No. (\%) } \\
\hline Lower back & $115(56.1)$ & $54(52.9)$ & $61(59.8)$ \\
\hline Hips & $78(38.0)$ & $39(38.2)$ & $39(38.2)$ \\
\hline Knees & $96(47.1)$ & $48(47.1)$ & $48(47.1)$ \\
\hline \multicolumn{4}{|l|}{ Shoe history } \\
\hline \multicolumn{4}{|c|}{ Worn shoes with heels higher than a hand width, No. (\%) } \\
\hline No, never & $116(56.9)$ & $55(53.9)$ & $61(59.8)$ \\
\hline Every now and then & $57(27.8)$ & $31(30.4)$ & $26(25.5)$ \\
\hline Regularly & $28(13.7)$ & $15(14.7)$ & $13(12.7)$ \\
\hline Almost always & $3(1.5)$ & $1(1.0)$ & $2(2.0)$ \\
\hline \multicolumn{4}{|c|}{ Bought shoes that were not comfortable, No. (\%) } \\
\hline No, never & $56(27.3)$ & $27(26.5)$ & $29(28.4)$ \\
\hline Every now and then & $124(60.8)$ & $62(60.2)$ & $62(60.8)$ \\
\hline Regularly & $16(7.8)$ & $8(7.8)$ & $8(7.8)$ \\
\hline Almost always & $7(3.4)$ & $5(4.9)$ & $2(2.0)$ \\
\hline Missing & $1(0.5)$ & & $1(1.0)$ \\
\hline \multicolumn{4}{|c|}{ Currently wears shoes that hurt the foot, No. (\%) } \\
\hline No, never & $84(41.0)$ & $43(42.2)$ & $41(40.2)$ \\
\hline Every now and then & $84(41.0)$ & $42(41.2)$ & $42(41.2)$ \\
\hline Regularly & $25(12.3)$ & $12(11.8)$ & $13(12.7)$ \\
\hline Almost always & $11(5.4)$ & $5(4.9)$ & $6(5.9)$ \\
\hline Missing & & $1(1.0)$ & \\
\hline
\end{tabular}


at baseline are reported in Table 1 and the locations of the foot pain at baseline are depicted in Figure 2. The baseline scores of the outcome measures for the entire population and the subgroups separately are reported in Table 1 . The differences between the study groups were small and were not found to be statistically significant.

\section{Intention-to-treat Analysis}

All data were not skewed more than 1.0 and were therefore deemed normally distributed. We found no differences between the study groups (Table 2). Footrelated pain and foot-related dysfunction decreased significantly in both intervention groups during the course of a year (Figure 3). Foot pain measured using the PI-NRS, FFI-5pt, and MFPDI decreased by approximately $25 \%(P<.001)$ after 3 months and by $40 \%(P<.001)$ after 12 months. Foot-related dysfunction measured using the FFI-5pt and MFPDI decreased by approximately $20 \%(P<.01)$ after 3 months and roughly by $35 \%$ after 12 months. Both general health and social participation did not change.

\section{Treatment Adherence and per Protocol Analysis}

In the per protocol analysis no differences were observed between the 2 intervention groups (Table 2). As for treatment adherence, 64 participants were adherent to the podiatric treatment and 71 participants to the footwear advice. The patient characteristics of those who were and who were not adherent are displayed in Table 3. The level of education and the history of buying uncomfortable shoes differ significantly between the adherent and nonadherent group.

\section{DISCUSSION}

The purpose of this study was to compare the effectiveness of podiatric treatment with standardized shoe advice for people aged 50 years and older with pain-related forefoot dysfunction in primary care. No differences in outcomes were found between participants who received shoe advice and those who were

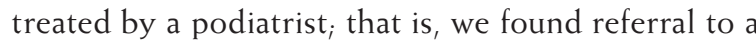
podiatrist was not superior to the provision of shoe advice. Both treatment groups improved with time, with a clinical important change $(>30 \%)$ observed in the PI-NRS score ${ }^{25,32}$ after 3 and 12 months.

Several explanations are to be considered. The first explanation is that both treatments have a similar positive effect. Another possibility is a regression toward the mean, as this study lacked a control group receiving no treatment. The level of forefoot pain (29.4 pts) and dysfunction (24.3 pts) measured with the FFI-5pt in our trial was higher than that measured in a cross- sectional study in the Netherlands (21.4 pts and 13.1 pts, respectively). ${ }^{26}$ Because our measurements were taken 5 times in a course of a year and we assessed multiple longitudinal improvements, regression to the mean is less likely. Another possible explanation is that the improvement in both groups was due to spontaneous improvement. One longitudinal study in which musculoskeletal pain was evaluated with a 5 -year follow-up ${ }^{33}$ described pain being chronic when it was present for more than 3 consecutive years. After personal communication with the authors of this study, we know that $23 \%$ of the people with foot pain had pain for 2 consecutive years, and $21 \%$ had pain at least at 1 more point during the follow-up. Around $40 \%$ of our participants had pain for more than 2 years before inclusion. These findings do not allow us to draw any conclusions about the probability of spontaneous improvement.

In a previous cross-sectional study in woman aged 50 years or older, we have shown that women who used our leaflet regardless of the presence of foot pain were able to find more appropriate shoes compared with those who did not use the leaflet. ${ }^{24}$ It is possible that wearing more appropriate and better fitting shoes reduces forefoot pain and its related dysfunction. We

\section{Figure 2. Prevalence of pain in 1 or 2 feet.}

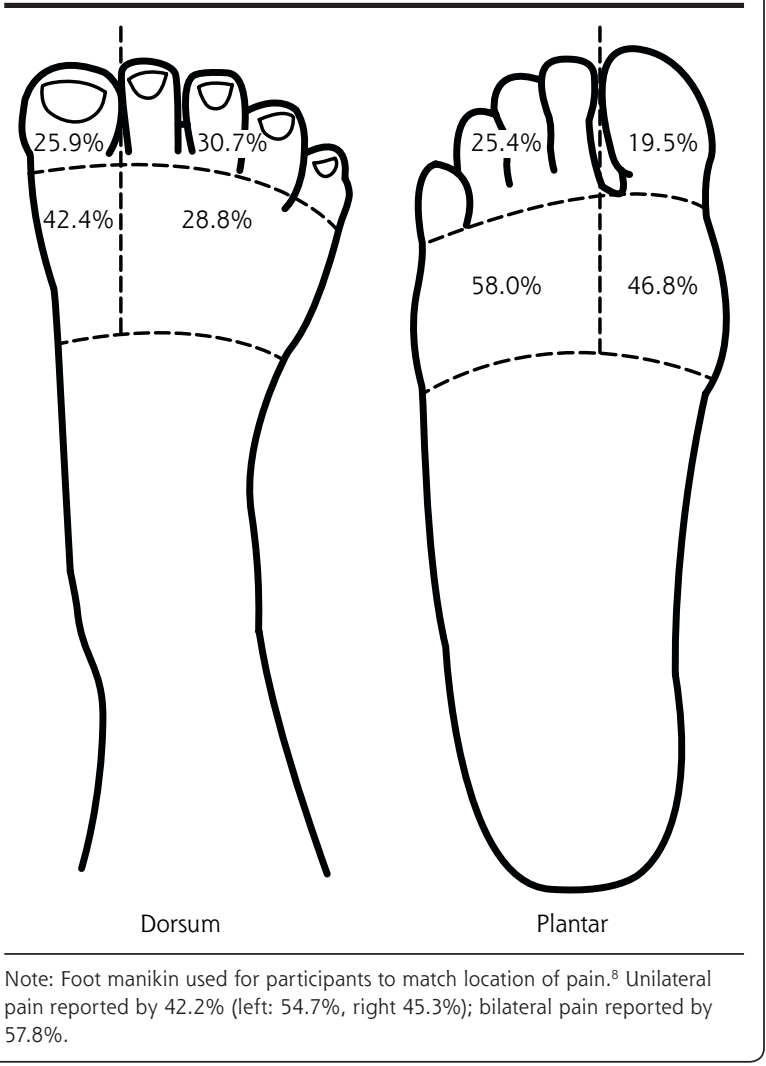




\begin{tabular}{|c|c|c|c|c|c|c|c|c|c|}
\hline $\begin{array}{l}\text { Instrument } \\
\text { (Score Range) }\end{array}$ & 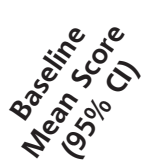 & 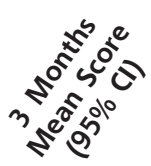 & $\frac{9}{4 x^{2}}$ & 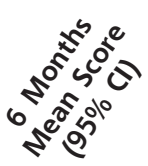 & $\frac{y^{2}}{x^{2}} x^{2}$ & 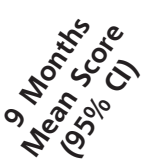 & $\frac{x^{5}}{x_{2}^{5}}$ & 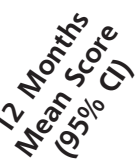 & 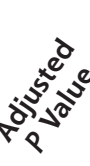 \\
\hline \multicolumn{10}{|c|}{ Intention-to-treat analysis: foot pain (lower score indicates less pain) } \\
\hline PI-NRS (0-10) & $\begin{array}{c}4.5 \\
(3.8-5.2)\end{array}$ & & & & & & & & \\
\hline Shoe advice & & $\begin{array}{c}3.4 \\
(2.6-4.1)\end{array}$ & .791 & $\begin{array}{c}3.2 \\
(2.5-3.9)\end{array}$ & .648 & $\begin{array}{c}2.8 \\
(2.0-3.5)\end{array}$ & .995 & $\begin{array}{c}2.7 \\
(1.9-3.5)\end{array}$ & .599 \\
\hline $\begin{array}{l}\text { Podiatric } \\
\text { treatment }\end{array}$ & & $\begin{array}{c}3.1 \\
(2.5-3.6)\end{array}$ & & $\begin{array}{c}2.9 \\
(2.3-3.4)\end{array}$ & & $\begin{array}{c}2.9 \\
(2.3-3.4)\end{array}$ & & $\begin{array}{c}2.3 \\
(1.7-2.8)\end{array}$ & \\
\hline FFI-5pt (0-100) & $\begin{array}{c}35.9 \\
(33.3-38.5)\end{array}$ & & & & & & & & \\
\hline Shoe advice & & $\begin{array}{c}29.3 \\
(24.6-34.0)\end{array}$ & .998 & $\begin{array}{c}24.0 \\
(18.9-29.1)\end{array}$ & .950 & $\begin{array}{c}24.3 \\
(18.8-29.7)\end{array}$ & .966 & $\begin{array}{c}21.0 \\
(15.8-26.2)\end{array}$ & .999 \\
\hline $\begin{array}{l}\text { Podiatric } \\
\text { treatment }\end{array}$ & & $\begin{array}{c}28.6 \\
(25.1-32.1)\end{array}$ & & $\begin{array}{c}25.1 \\
(21.2-29.0)\end{array}$ & & $\begin{array}{c}25.3 \\
(21.1-29.4)\end{array}$ & & $\begin{array}{c}21.1 \\
(17.3-25.0)\end{array}$ & \\
\hline MFPDI $(0-10)$ & $\begin{array}{c}4.8 \\
(4.4-5.1)\end{array}$ & & & & & & & & \\
\hline Shoe advice & & $\begin{array}{c}3.6 \\
(2.9-4.2)\end{array}$ & .997 & $\begin{array}{c}3.3 \\
(2.7-4.0)\end{array}$ & .995 & $\begin{array}{c}3.2 \\
(2.6-3.9)\end{array}$ & .955 & $\begin{array}{c}2.9 \\
(2.2-3.6)\end{array}$ & $>.999$ \\
\hline $\begin{array}{l}\text { Podiatric } \\
\text { treatment }\end{array}$ & & $\begin{array}{c}3.5 \\
(3.0-4.0)\end{array}$ & & $\begin{array}{c}3.4 \\
(2.9-3.8)\end{array}$ & & $\begin{array}{c}3.4 \\
(2.9-3.9)\end{array}$ & & $\begin{array}{c}2.9 \\
(2.4-3.4)\end{array}$ & \\
\hline \multicolumn{10}{|c|}{ Intention-to-treat analysis: foot function (lower score indicates less dysfunction) } \\
\hline FFI-5pt (0-100) & $\begin{array}{c}21.3 \\
(18.6-24.0)\end{array}$ & & & & & & & & \\
\hline Shoe advice & & $\begin{array}{c}18.8 \\
(14.6-23.0)\end{array}$ & .999 & $\begin{array}{c}15.6 \\
(11.0-20.3)\end{array}$ & .994 & $\begin{array}{c}15.1 \\
(10.4-19.9)\end{array}$ & .937 & $\begin{array}{c}14.8 \\
(10.0-19.5)\end{array}$ & .972 \\
\hline $\begin{array}{l}\text { Podiatric } \\
\text { treatment }\end{array}$ & & $\begin{array}{c}18.6 \\
(15.5-21.8)\end{array}$ & & $\begin{array}{c}15.7 \\
(12.0-19.3)\end{array}$ & & $\begin{array}{c}15.6 \\
(11.9-19.4)\end{array}$ & & $\begin{array}{c}14.0 \\
(10.3-17.6)\end{array}$ & \\
\hline MFPDI (0-18) & $\begin{array}{c}6.2 \\
(5.5-6.8)\end{array}$ & & & & & & & & \\
\hline Shoe advice & & $\begin{array}{c}5.4 \\
(4.4-6.4)\end{array}$ & .323 & $\begin{array}{c}4.4 \\
(3.4-5.3)\end{array}$ & .958 & $\begin{array}{c}4.4 \\
(3.4-5.4)\end{array}$ & .961 & $\begin{array}{c}4.1 \\
(3.1-5.0)\end{array}$ & .765 \\
\hline $\begin{array}{l}\text { Podiatric } \\
\text { treatment }\end{array}$ & & $\begin{array}{c}4.7 \\
(4.1-5.4)\end{array}$ & & $\begin{array}{c}4.2 \\
(3.5-4.9)\end{array}$ & & $\begin{array}{c}4.2 \\
(3.5-4.9)\end{array}$ & & $\begin{array}{c}3.7 \\
(3.0-4.4)\end{array}$ & \\
\hline \multicolumn{10}{|c|}{ Protocol analysis: foot pain (lower score indicates less pain) } \\
\hline PI-NRS(0-10) & $\begin{array}{c}4.1 \\
(3.6-4.5)\end{array}$ & & & & & & & & \\
\hline Shoe advice & & $\begin{array}{c}2.8 \\
(2.0-3.7)\end{array}$ & .944 & $\begin{array}{c}3.4 \\
(2.4-4.3)\end{array}$ & .436 & $\begin{array}{c}3.3 \\
(2.3-4.4)\end{array}$ & .966 & $\begin{array}{c}2.1 \\
(1.2-2.9)\end{array}$ & .386 \\
\hline $\begin{array}{l}\text { Podiatric } \\
\text { treatment }\end{array}$ & & $\begin{array}{c}3.1 \\
(2.4-3.8)\end{array}$ & & $\begin{array}{c}2.7 \\
(2.0-3.4)\end{array}$ & & $\begin{array}{c}3.1 \\
(2.3-3.9)\end{array}$ & & $\begin{array}{c}2.7 \\
(2.0-3.4)\end{array}$ & \\
\hline FFl-5pt (0-100) & $\begin{array}{c}28.4 \\
(24.0-32.7)\end{array}$ & & & & & & & & \\
\hline Shoe advice & & $\begin{array}{c}26.0 \\
(17.6-34.3)\end{array}$ & .931 & $\begin{array}{c}24.1 \\
(15.8-32.4)\end{array}$ & .934 & $\begin{array}{c}24.2 \\
(15.7-32.8)\end{array}$ & .970 & $\begin{array}{c}23.7 \\
(19.5-27.9)\end{array}$ & .961 \\
\hline $\begin{array}{l}\text { Podiatric } \\
\text { treatment }\end{array}$ & & $\begin{array}{c}23.7 \\
(16.4-30.9)\end{array}$ & & $\begin{array}{c}26.3 \\
(18.9-33.8)\end{array}$ & & $\begin{array}{c}22.5 \\
(15.1-29.9)\end{array}$ & & $\begin{array}{c}21.5 \\
(13.3-29.8)\end{array}$ & \\
\hline MFPDI $(0-10)$ & $\begin{array}{c}4.8 \\
(4.4-5.3)\end{array}$ & & & & & & & & \\
\hline Shoe advice & & $\begin{array}{c}3.3 \\
(2.5-4.1)\end{array}$ & .779 & $\begin{array}{c}3.4 \\
(2.6-4.3)\end{array}$ & .868 & $\begin{array}{c}3.4 \\
(2.5-4.3)\end{array}$ & .924 & $\begin{array}{c}2.9 \\
(2.0-3.9)\end{array}$ & $>.999$ \\
\hline $\begin{array}{l}\text { Podiatric } \\
\text { treatment }\end{array}$ & & $\begin{array}{c}3.7 \\
(3.1-4.3)\end{array}$ & & $\begin{array}{c}3.2 \\
(2.5-3.8)\end{array}$ & & $\begin{array}{c}3.2 \\
(2.6-3.9)\end{array}$ & & $\begin{array}{l}3.0 \\
(2.3-3.7)\end{array}$ & \\
\hline \multicolumn{10}{|c|}{ Protocol analysis: foot function (lower score indicates less dysfunction) } \\
\hline FFl-5pt (0-100) & $\begin{array}{c}22.5 \\
(19.2-25.8)\end{array}$ & & & & & & & & \\
\hline Shoe advice & & $\begin{array}{c}18.2 \\
(12.7-23.6)\end{array}$ & .961 & $\begin{array}{c}16.2 \\
(10.0-22.4)\end{array}$ & .808 & $\begin{array}{c}16.2 \\
(9.9-22.6)\end{array}$ & .790 & $\begin{array}{c}13.8 \\
(7.6-19.9)\end{array}$ & .903 \\
\hline $\begin{array}{l}\text { Podiatric } \\
\text { treatment }\end{array}$ & & $\begin{array}{c}17.5 \\
(13.8-21.2)\end{array}$ & & $\begin{array}{c}14.4 \\
(10.2-18.7)\end{array}$ & & $\begin{array}{c}14.3 \\
(10.0-18.6)\end{array}$ & & $\begin{array}{c}15.0 \\
(10.6-19.4)\end{array}$ & \\
\hline MFPDI (0-18) & $\begin{array}{c}5.6 \\
(4.8-6.4)\end{array}$ & & & & & & & & \\
\hline Shoe advice & & $\begin{array}{c}4.6 \\
(3.3-5.8)\end{array}$ & .999 & $\begin{array}{c}3.8 \\
(2.6-5.0)\end{array}$ & .814 & $\begin{array}{c}3.8 \\
(2.5-5.0)\end{array}$ & .808 & $\begin{array}{c}3.5 \\
(2.1-4.8)\end{array}$ & .993 \\
\hline $\begin{array}{l}\text { Podiatric } \\
\text { treatment }\end{array}$ & & $\begin{array}{c}4.6 \\
(3.7-5.5)\end{array}$ & & $\begin{array}{c}3.4 \\
(2.5-4.3)\end{array}$ & & $\begin{array}{c}3.4 \\
(2.4-4.3)\end{array}$ & & $\begin{array}{c}3.6 \\
(2.6-4.6)\end{array}$ & \\
\hline
\end{tabular}

PI-NRS = pain intensity numeric rating scale; FFI-5pt = foot function index 5-point answer; MFPDI = Manchester foot pain and disability index.

a Adjusted $P$ values: foot pain, 1-(1-p)^3; foot function, 1-(1-p)^2 (Šídák method). 
are aware, however, that the effectiveness of the shoe leaflet was tested in a different population and did not bear on foot pain and function. Moreover, the lack of a control group in our trial does not allow for a definite conclusion.

The lack of effect of podiatric treatment compared with shoe advice found in this study could be the result of the heterogeneous effect of podiatry, as mentioned in other studies. ${ }^{34-36}$ This possibility is supported by a process analysis using participants from the current randomized controlled trial, in which we have shown that the approach to assess cause by podiatric inspection and examination in our study is heterogeneous as well. ${ }^{37}$

A strength of this pragmatic randomized controlled trial is that it closely replicates daily practice and evaluates 2 common treatments for forefoot problems encountered by general physicians. ${ }^{16}$ Another strength is that we are able to interpret our findings in greater depth because we have evaluated the process of the 2 interventions in other studies. ${ }^{24,37}$ Additionally, the important constructs foot pain and foot-related dysfunction were measured using different instruments that showed comparable outcomes, which supports the reliability of our results.

On the other hand, the results of this study have to be interpreted in light of the study limitations. During the inclusion period, we recorded the numbers of the prospective participants applying for extensive trial information and a screening form (Figure 1). The number of prospective participants who decided not to participate after receiving initial information about the study is unknown, however, because potential participants could seek information from multiple resources (the general practitioner, physician assistant, a short information leaflet, or calling the researcher or research assistants). Based on retrospective information, we estimate this number to be least 3 dozen patients, and most "just wanted to be treated by a podiatrist and not to be allocated." The implication is that the effect of the shoe advice might be an overestimation of the real effect $t_{i}$ ie, the willingness to try shoe advice could be lower in the general population than in our study.

Figure 3. Change in foot-related pain and dysfunction with time.
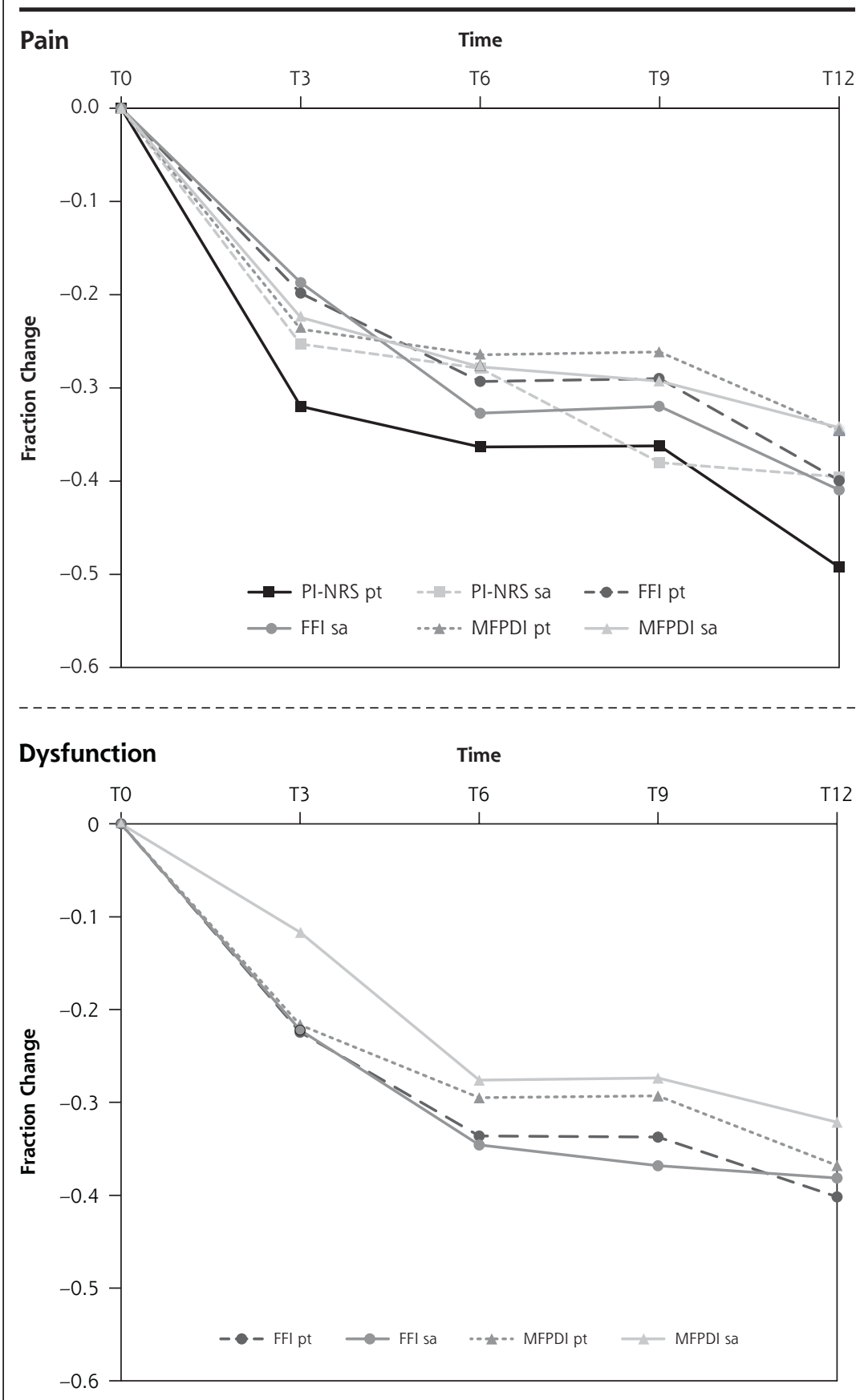

$\mathrm{FFI}=$ foot function index; MFPDI = Manchester Foot Pain and Disability Index; PI-NRS = pain intensity numeric rating scale; $\mathrm{pt}=$ podiatric treatment; sa $=$ shoe advice 
Table 3. Participants' Baseline Characteristics by Adherence Group

\begin{tabular}{|c|c|c|c|}
\hline Variable & $\begin{array}{c}\text { Total } \\
\text { Population } \\
\mathbf{N}=205\end{array}$ & $\begin{array}{l}\text { Nonadherent } \\
n=70\end{array}$ & $\begin{array}{c}\text { Adherent } \\
\mathrm{n}=135\end{array}$ \\
\hline \multicolumn{4}{|l|}{ Demographic characteristic } \\
\hline Age (SD), y & $64(9.3)$ & $65(9.0)$ & $64(9.5)$ \\
\hline Sex, female, No. (\%) & $159(77.9)$ & $51(72.9)$ & $108(80)$ \\
\hline $\begin{array}{l}\text { Allocation to podiatric treatment, } \\
\text { No. (\%) }\end{array}$ & $102(49.8)$ & $37(52.9)$ & $64(47.4)$ \\
\hline \multicolumn{4}{|l|}{$\begin{array}{l}\text { First attention to research project, } \\
\text { No. (\%) }\end{array}$} \\
\hline Letter from general practitioner & $52(25.4)$ & $16(22.9)$ & $35(25.9)$ \\
\hline During visit to general practitioner & $76(37.1)$ & $26(37.1)$ & $50(37)$ \\
\hline Poster in waiting area & $44(21.5)$ & $13(18.6)$ & $31(23)$ \\
\hline Other & $30(14.7)$ & $13(18.6)$ & $17(12.6)$ \\
\hline \multicolumn{4}{|l|}{ Education, No. (\%) ${ }^{\mathrm{a}}$} \\
\hline Primary school & $17(8.3)$ & $9(12.9)$ & $8(5.9)$ \\
\hline High school & $45(22.0)$ & $17(24.2)$ & $28(20.7)$ \\
\hline Vocational training & $77(37.7)$ & $22(31.4)$ & $55(40.7)$ \\
\hline Bachelor degree & $41(20.0)$ & $17(24.37)$ & $28(20.7)$ \\
\hline Master degree or higher & $20(9.8)$ & $11(15.7)$ & $9(6.7)$ \\
\hline \multicolumn{4}{|l|}{ Pain history } \\
\hline \multicolumn{4}{|l|}{$\begin{array}{l}\text { Duration of pain before inclusion, } \\
\text { No. (\%) }\end{array}$} \\
\hline $3-6 \mathrm{mo}$ & $49(23.9)$ & $14(20)$ & $35(25.9)$ \\
\hline $6-12 \mathrm{mo}$ & $23(11.2)$ & $12(17.1)$ & $11(8.1)$ \\
\hline $12-24 \mathrm{mo}$ & $33(16.1)$ & $8(11.4)$ & $25(18.5)$ \\
\hline$>24 \mathrm{mo}$ & $92(44.9)$ & $31(44.3)$ & $61(45.2)$ \\
\hline Missing & $8(3.9)$ & $4(5.7)$ & $4(3)$ \\
\hline $\begin{array}{l}\text { Missed work due to foot problems } \\
\text { in last } 3 \mathrm{mo} \text {, No. }(\%)^{\mathrm{b}}\end{array}$ & $8(11.9)$ & $2(9)$ & $6(13.3)$ \\
\hline \multicolumn{4}{|l|}{$\begin{array}{l}\text { Pain in other joints lower extremity } \\
\text { in last month, No. (\%) }\end{array}$} \\
\hline Lower back & $115(56.1)$ & $35(50)$ & $80(59.3)$ \\
\hline Hips & 78 (38.0) & $24(34.3)$ & $54(40)$ \\
\hline Knees & $96(47.1)$ & $29(41.4)$ & 67 (49.6) \\
\hline \multicolumn{4}{|l|}{ Shoe history } \\
\hline \multicolumn{4}{|l|}{$\begin{array}{l}\text { Worn shoes with heels higher than } \\
\text { a hand width, No. (\%) }\end{array}$} \\
\hline No, never & $116(56.9)$ & $41(58.6)$ & $75(55.6)$ \\
\hline Every now and then & $57(27.8)$ & $18(25.7)$ & $39(28.9)$ \\
\hline Regularly & $28(13.7)$ & $10(14.3)$ & $18(13.3)$ \\
\hline Almost always & $3(1.5)$ & $0(0)$ & $3(2.2)$ \\
\hline \multicolumn{4}{|l|}{$\begin{array}{l}\text { Bought shoes that were not com- } \\
\text { fortable, No. }(\%)^{\text {a }}\end{array}$} \\
\hline No, never & $56(27.3)$ & $27(38.5)$ & $29(21.5)$ \\
\hline Every now and then & $124(60.8)$ & $37(52.9)$ & $87(64.4)$ \\
\hline Regularly & $16(7.8)$ & $3(4.3)$ & $13(9.6)$ \\
\hline Almost always & $7(3.4)$ & $2(2.9)$ & $5(3.7)$ \\
\hline \multicolumn{4}{|l|}{$\begin{array}{l}\text { Currently wears shoes that hurt the } \\
\text { foot, No. (\%) }\end{array}$} \\
\hline No, never & $84(41.0)$ & $33(47.1)$ & $51(40.2)$ \\
\hline Every now and then & $84(41.0)$ & $23(32.9)$ & $61(45.2)$ \\
\hline Regularly & $25(12.3)$ & 8 (11.4) & 17 (12.6) \\
\hline Almost always & $11(5.4)$ & $5(7.1)$ & $6(4.4)$ \\
\hline
\end{tabular}

Another limitation is that the percentage of women participating in our study was higher compared with the prevalence reported by other studies, ${ }^{4,5,7,8}$ which, based on the amount of female foot and shoe fit studies, limits the generalizability somewhat. $^{38-41}$

In light of our results, we would advise primary care physicians to provide shoe advice to a patient with forefoot pain before referring to a podiatrist. Our study results also suggest that a podiatrist should offer a patient the option of shoe advice instead of manufacturing an orthotic, thus giving a patient a choice between different levels of expense.

When a patient is unwilling to accept shoe advice as a therapy, referral to the podiatrist is an alternative that is as effective as a shoe advice, but more expensive.

To read or post commentaries in response to this article, see it online at http://www. annfammed.org/content/12/5/432.

Key words: foot; foot orthotics; podiatry; shoes; general practitioners

Submitted October 1, 2013; submitted, revised, May 1, 2014; accepted June 2, 2014.

Funding support: This study was funded by the Netherlands Organisation for Health Research and Development (ZonMw; dossier number: 42011003).

Acknowledgments: We have obtained permission from ISIS outcomes to use the MFPDI questionnaire. We would like to thank all our participants for their time and willingness to fill out the questionnaires. And we would like to thank Dr Thielke for providing us with additional information about his interesting longitudinal study.

Supplementary materials: Available at http://www.AnnFamMed.org/ content/12/5/432/suppl/DC1/

\section{References}

1. Menz HB, Jordan KP, Roddy E, Croft PR. Characteristics of primary care consultations for musculoskeletal foot and ankle problems in the UK. Rheumatology (Oxford). 2010;49(7):1391-1398. 
2. Thomas MJ, Roddy E, Zhang W, Menz HB, Hannan MT, Peat GM. The population prevalence of foot and ankle pain in middle and old age: a systematic review. Pain. 2011;152(12):2870-2880.

3. van der Waal JM, Bot SDM, Terwee CB, et al. The incidences of and consultation rate for lower extremity complaints in general practice. Ann Rheum Dis. 2006;65(6):809-815.

4. Gorter KJ, Kuyvenhoven MM, de Melker RA. Nontraumatic foot complaints in older people. A population-based survey of risk factors, mobility, and well-being. J Am Podiatr Med Assoc. 2000;90(8):397-402.

5. Menz HB, Tiedemann A, Kwan MMS, Plumb K, Lord SR. Foot pain in community-dwelling older people: an evaluation of the Manchester Foot Pain and Disability Index. Rheumatology (Oxford). 2006;45(7):863-867.

6. Dufour $A B$, Broe KE, Nguyen US, et al. Foot pain: is current or past shoewear a factor? Arthritis Rheum. 2009;61(10):1352-1358.

7. Hill CL, Gill TK, Menz HB, Taylor AW. Prevalence and correlates of foot pain in a population-based study: the North West Adelaide health study. J Foot Ankle Res. 2008;1(1):2.

8. Garrow AP, Silman AJ, Macfarlane GJ. The Cheshire Foot Pain and Disability Survey: a population survey assessing prevalence and associations. Pain. 2004;110(1-2):378-384.

9. Gorter K, Kuyvenhoven M, de Melker R. Health care utilisation by older people with non-traumatic foot complaints. What makes the difference? Scand J Prim Health Care. 2001;19(3):191-193.

10. Barr ELM, Browning C, Lord SR, Menz HB, Kendig H. Foot and leg problems are important determinants of functional status in community dwelling older people. Disabil Rehabil. 2005;27(16):917-923.

11. Menz HB, Morris ME, Lord SR. Foot and ankle risk factors for falls in older people: a prospective study. J Gerontol A Biol Sci Med Sci. 2006;61(8):866-870.

12. Keenan AM, Tennant A, Fear J, Emery P, Conaghan PG. Impact of multiple joint problems on daily living tasks in people in the community over age fifty-five. Arthritis Rheum. 2006;55(5):757-764.

13. Bergin SM, Munteanu SE, Zammit GV, Nikolopoulos N, Menz HB. Impact of first metatarsophalangeal joint osteoarthritis on health-related quality of life. Arthritis Care Res (Hoboken). 2012;64(11):1691-1698

14. Chen J, Devine A, Dick IM, Dhaliwal SS, Prince RL. Prevalence of lower extremity pain and its association with functionality and quality of life in elderly women in Australia. J Rheumatol. 2003;30(12):2689-2693.

15. Gilheany MF, Landorf KB, Robinson P. Hallux valgus and hallux rigidus: a comparison of impact on health-related quality of life in patients presenting to foot surgeons in Australia. J Foot Ankle Res. 2008;1(1):14.

16. Gorter K, de Poel S, de Melker R, Kuyvenhoven M. Variation in diagnosis and management of common foot problems by GPs. Fam Pract. 2001;18(6):569-573.

17. Torkki M, Malmivaara A, Seitsalo S, Hoikka V, Laippala P, Paavolainen P. Surgery vs orthosis vs watchful waiting for hallux valgus: a randomized controlled trial. JAMA. 2001;285(19):2474-2480.

18. Zuijderduin WM, Dekker J. Diagnoses and interventions in podiatry. Disabil Rehabil. 1996;18(1):27-34.

19. Burns SL, Leese GP, McMurdo MET. Older people and ill fitting shoes. Postgrad Med J. 2002;78(920):344-346.

20. Keegan TH, Kelsey JL, King AC, Quesenberry CP Jr, Sidney S. Characteristics of fallers who fracture at the foot, distal forearm, proximal humerus, pelvis, and shaft of the tibia/fibula compared with fallers who do not fracture. Am J Epidemiol. 2004;159(2):192-203.

21. Menz HB, Morris ME. Footwear characteristics and foot problems in older people. Gerontology. 2005;51(5):346-351.
22. Tencer AF, Koepsell TD, Wolf ME, et al. Biomechanical properties of shoes and risk of falls in older adults. J Am Geriatr Soc. 2004;52(11):1840-1846.

23. van der Zwaard BC, Elders PJ, Knol DL, et al. Treatment of forefoot problems in older people: study protocol for a randomised clinical trial comparing podiatric treatment to standardised shoe advice. J Foot Ankle Res. 2011;4(1):11.

24. van der Zwaard BC. Poppe E, Vanwanseele B, van der Horst $H E$, Elders PJ. Development and evaluation of a leaflet containing shoe advice: a randomised controlled trial. Fam Pract. 2014;31(3):267-272.

25. Farrar JT, Young JPJ Jr, LaMoreaux L, Werth JL, Poole RM. Clinical importance of changes in chronic pain intensity measured on an 11-point numerical pain rating scale. Pain. 2001;94(2):149-158.

26. Kuyvenhoven MM, Gorter KJ, Zuithoff P, Budiman-Mak E, Conrad $\mathrm{KJ}$, Post MWM. The foot function index with verbal rating scales (FFI-5pt): A clinimetric evaluation and comparison with the original FFI. J Rheumatol. 2002;29(5):1023-1028.

27. Garrow AP, Papageorgiou AC, Silman AJ, Thomas E, Jayson MI, Macfarlane GJ. Development and validation of a questionnaire to assess disabling foot pain. Pain. 2000;85(1-2):107-113.

28. Ware J Jr, Kosinski M, Keller SD. A 12-Item Short-Form Health Survey: construction of scales and preliminary tests of reliability and validity. Med Care. 1996;34(3):220-233.

29. Wilkie R, Peat G, Thomas E, Hooper H, Croft PR. The Keele Assessment of Participation: a new instrument to measure participation restriction in population studies. Combined qualitative and quantitative examination of its psychometric properties. Qual Life Res. 2005;14(8):1889-1899.

30. MLwiN Version 2.1 [computer program]. Centre for Multilevel Modelling, University of Bristol; 2009.

31. Fitzmaurice GM, Laird NM, Ware JH. Applied Longitudinal Analysis. New York, NY: Wiley; 2004.

32. Menz HB, Lord SR. Foot problems, functional impairment, and falls in older people. J Am Podiatr Med Assoc. 1999;89(9):458-467.

33. Thielke SM, Whitson $\mathrm{H}$, Diehr $\mathrm{P}$, et al. Persistence and remission of musculoskeletal pain in community-dwelling older adults: results from the cardiovascular health study. J Am Geriatr Soc. 2012;60(8):1393-1400.

34. Chevalier TL, Chockalingam N. Effects of foot orthoses: How important is the practitioner? Gait Posture. 2012;35(3):383-388.

35. Guldemond NA, Leffers $P$, Schaper NC, Sanders AP, Nieman FH, Walenkamp GH. Comparison of foot orthoses made by podiatrists, pedorthists and orthotists regarding plantar pressure reduction in The Netherlands. BMC Musculoskelet Disord. 2005;6:61.

36. Hawke F, Burns J, Radford JA, du Toit V. Custom-made foot orthoses for the treatment of foot pain. Cochrane Database Syst Rev. 2008;(3):CD006801.

37. van der Zwaard BC, Swagerman WJ, Vanwanseele B, Gorter KJ, van der Horst HE, Elders PJ. Process evaluation of podiatric treatment of patients with forefoot pain. J Foot Ankle Res. 2013;6(1):32.

38. Au EY, Goonetilleke RS. A qualitative study on the comfort and fit of ladies' dress shoes. Appl Ergon. 2007;38(6):687-696.

39. Frey C, Thompson F, Smith J, Sanders M, Horstman H. American Orthopaedic Foot and Ankle Society women's shoe survey. Foot Ankle. 1993;14(2):78-81.

40. Frey C. Foot health and shoewear for women. Clin Orthop Relat Res. 2000;(372):32-44.

41. Goud A, Khurana B, Chiodo C, Weissman BN. Women's musculoskeletal foot conditions exacerbated by shoe wear: an imaging perspective. Am J Orthop (Belle Mead NJ). 2011;40(4):183-191. 